\title{
A Matter of Trust?: A Study of Coordination of Swedish Stakeholders in Return-to-Work
}

Christian Ståhl, Tommy Svensson, Gunilla Petersson and Kerstin Ekberg

The self-archived postprint version of this journal article is available at Linköping University Institutional Repository (DiVA):

http:// urn.kb.se/ resolve?urn=urn:nbn:se:liu:diva-21379

N.B.: When citing this work, cite the original publication.

The original publication is available at www.springerlink.com:

Ståhl, C., Svensson, T., Petersson, G., Ekberg, K., (2010), A Matter of Trust?: A Study of Coordination of Swedish Stakeholders in Return-to-Work, J ournal of occupational rehabilitation, 20, 299-310. https:// doi.org/ 10.1007/ s10926-009-9205-0

Original publication available at:

https:// doi.org/ 10.1007/ s10926-009-9205-0

Copyright: Springer Verlag (Germany)

http:// www.springerlink.com/ ?MUD=MP 


\section{A matter of trust? A study of coordination of Swedish stakeholders in return-to-work}

Christian Ståhl ${ }^{1,2 *}$, Tommy Svensson ${ }^{3,4}$, Gunilla Petersson ${ }^{3}$, Kerstin Ekberg ${ }^{1,2}$

${ }^{1}$ National Centre for Work and Rehabilitation, Department of Medical and Health

Sciences, Linköping University, Linköping, Sweden

${ }^{2}$ HELIX VINN Excellence Centre, Linköping University, Linköping, Sweden

${ }^{3}$ Department of Behavioural Sciences and Learning, Division of Sociology,

Linköping University, Linköping, Sweden

${ }^{4}$ Nordic School of Public Health, Göteborg, Sweden

* Corresponding author

Email addresses:

CS: christian.stahl@liu.se

TS: tommy.svensson@liu.se

GP: gunilla.e.petersson@liu.se

KE: kerstin.ekberg@liu.se

Running head: A matter of trust?

Christian Ståhl

National Centre for Work and Rehabilitation

Department of Medical and Health Sciences

Linköping University

58183 Linköping

Sweden

+46 (0) 13 - 221457 


\section{Abstract}

Introduction Stakeholder cooperation in return-to-work has been increasingly emphasized over the last years. However, there is a lack of empirical studies on the subject. This study explores different public stakeholders' experiences of participating in Coordination Associations (CAs), a Swedish form of structured cooperation in return-to-work. The aim of the study is to determine the impact of stakeholder interests on the prerequisites for cooperation.

Methods Thirty-five representatives from two CAs in eastern Sweden were interviewed regarding the aim, structure and strategies for their common work.

Results Stakeholders' actions are to a high degree determined by their institutional preferences and self-interest. In the CAs, the motives for cooperation differ, and although these differences supposedly could be overcome, they are in fact not. One of the stakeholders, the Public Employment Service, limit its interest to coordinating resources, while the other three wishes to engage in elaborated cooperative work forms, implying the crossing of organizational borders. This discrepancy can largely be attributed to the difficulties for representatives from national authorities in changing their priorities in order to make cooperation work.

Conclusions Stakeholders’ interests have a high impact on the prerequisites for cooperation in return-to-work. By referring to organizational goals, stakeholders engage in non-cooperative behaviour, which threatens to spoil cooperative initiatives and to develop distrust in cooperative work forms. The results of this study expose the 
complexity of and threats to cooperation, and its conclusions may be used by returnto-work stakeholders in different jurisdictions to improve the possibilities for the development of cooperative structures.

Keywords: coordination; cooperation; return-to-work; welfare; trust; Sweden 


\section{Introduction}

In an increasing number of studies, a cooperative multi-stakeholder approach to return-to-work has been emphasized [1-5]. However, substantial communication problems between return-to-work stakeholders are noted, and with goodwill and trust as key conditions, intermediary actors are argued as having the potential of facilitating a cooperative return-to-work process [6]. Several studies have also noted a need for research on the financial, legal and competence aspects of stakeholder cooperation [2, 5].

The issue of stakeholder cooperation in managing return-to-work raises several questions, for instance how stakeholder cooperation should be organized in order to create a structure in which all stakeholders can comply with the overall aim. Further, it is not clear how strong the cohesion between the stakeholders needs to be, and in what way this cohesion should be regulated. In answering these questions, one will need to take into account the institutional structure of the social security system in which the return-to-work is to take place, due to the different logics of different welfare states $[7,8]$.

The stakeholder concept can be defined differently: it can refer either to organizations or to individuals. In the return-to-work literature, for instance, the disabled person is seen as a stakeholder just as well as the compensation system or the employer. Stakeholder theory has often treated stakeholders as homogenous groups, failing to distinguish the characteristics or attitudes of individuals $[9,10]$. Central to stakeholder theory is that stakeholders represent different interests, which can be attributed to organizations, groups or individuals. In this study, a stakeholder is defined as an 
organization or an authority that has an interest in or a responsibility for the return-towork process, or an individual representing such an organization or an authority. This implies that the individual can be expected to, but will not necessarily, act on the basis of organizational interests.

\section{Coordinating stakeholders' responsibilities in the Swedish welfare system}

The Swedish social security system is to be understood in the context of the Nordic welfare model, which has been described as a social-democratic [7] or an encompassing welfare regime [11]. Sweden has a long history of active labour market policies (ALMPs), and an emphasis on employment and return-to-work is prevalent both in the unemployment benefit schemes and in the sickness insurance system. The Scandinavian countries are high spenders on ALMPs, and Sweden is the highest spender among the Scandinavian countries [12]. Also, Swedish welfare institutions have far-reaching responsibilities for its citizens’ welfare through an emphasis on income security for the socially disadvantaged.

In the Swedish welfare system, there are four principal stakeholders that have responsibility for rehabilitation: the Swedish Social Insurance Agency (SSIA), the Swedish Public Employment Service (SPES), municipalities and primary healthcare. These stakeholders have responsibilities for different aspects of an individual's rehabilitation. The social insurance agency is responsible for distributing sickness benefits, for assessing the work ability of the clients, and to coordinate the rehabilitation back to work. The employment service is responsible for employment guidance, vocational rehabilitation and education aiming to help people get employment. The healthcare system, organized through county councils, is responsible for medical care, treatment and rehabilitation, and for providing medical 
information to the social insurance agency regarding level of functioning and an initial assessment of work ability. Municipal social services are responsible for social rehabilitation, i.e. to strengthen individuals’ opportunities to lead independent lives. Most municipalities manage activities to help people with social allowances to return to work. Apart from the public authorities, employers are involved by being responsible for rehabilitation within the workplace.

There has been a growing political discontent with the sectorized responsibility for rehabilitation, since it involves a risk that disadvantaged people will suffer from the conflicting priorities of welfare agencies. A set of pilot programmes was initiated in local areas in the 1990s, resulting in several arenas for cooperation between the public authorities. For instance, specific cooperative work routines have been initiated between the social insurance agency and the employment service to manage people who are both sick and unemployed.

In 2004, a permanent legislation of stakeholder cooperation took place: the Financial Coordination of Rehabilitation Measures Act (FINSAM), which represents the most structured form of stakeholder cooperation yet. In the legislation, it is stated that financial coordination can be carried out through the forming of Coordination Associations (CAs), with municipalities, healthcare services, the social insurance agency and the employment service as participating authorities. According to FINSAM, CAs are to operate on a local municipal level with measures targeted to people in need of coordinated rehabilitation from more than one of the participating stakeholders, for instance long-term sick, disabled or unemployed. The CAs are 
thought to facilitate return-to-work for individuals and to conduce to a more costeffective use of available resources.

FINSAM also regulates the organizational form of the CAs, where the associations are formed as separate organizations with pooled budgets of a maximum of $5 \%$ of the budgeted cost for sickness benefits in the working district. Every CA involves a local political board and an office with a coordinator. In public law, a CA is considered a legal person, which implies that the state authorities, the municipalities and the county councils share the legal responsibility for decisions regarding a specific target group. By April 2008, 65 CAs had been formed, involving 120 of Sweden’s 290 municipalities.

\section{[Figure 1 about here]}

The boards of the CAs consist of representatives from the four stakeholders, including officials from the two public authorities (the social insurance agency and the employment service) and political representatives from the municipality and the county council. The boards decide what course of action the CA should take, and administrate the pooled budget. An operative group of managers from the participating stakeholders has the dual purpose of preparing tasks for the board and putting the board's decisions into practice. Thus, a CA can be considered a separate organization, built by representatives and financial contributions from the four stakeholders (see figure 1). 
CA activities include both broadly oriented work forms, such as interdisciplinary teams in handling sick-listings, and more targeted work forms, such as integration of immigrants or interorganizational teams that work with long-term unemployed. Thus, the CAs comprise preventive and promotive activities as well as occupational and socio-medical activities, aiming for activation and early return-to-work [13].

It should be noted that the CAs do not limit their scope to coordinating existing services; rather, they play an active part in initiating concrete cooperative and collaborative work between stakeholders. However, these concepts often become intertwined. This study proceeds from the following distinction between the concepts:

- Cooperation describes a situation where two or more organisations systematically design their decision-making or work processes so that those working in the organisations can cooperate in the accomplishment of a mutual goal;

- Collaboration means that people communicate within or between organisations to achieve common goals;

- Coordination is used to mean that different systems in the social sector are in concurrence. Coordination can relate to financing, political decisions, administrative management, rules and regulations in various benefits systems, premises, functional support, etc. [14]

The aim of this study is to explore the participating stakeholders' views on and experiences of participating in a CA, which will be elucidated through the following research questions.

1. What is the impact of stakeholder interests on the prerequisites for coordination and/or cooperation?

2. What consequences do stakeholder interests have on the CAs' possibilities of functioning as an intermediary actor in return-to-work? 


\section{Methods}

This study is an explorative investigation of the prerequisites for cooperation within the setting of a CA. In order to make an exploratory approach possible, a qualitative perspective for data collection was chosen, with semi-structured interviews as the method of inquiry.

\section{Selection of respondents}

Two CAs in eastern Sweden were contacted for inclusion in the study. The two CAs were selected both out of convenience, since they are located in the same county, and strategically, since they work under different demographical conditions: one is located in a medium-sized city, while the other consists of two smaller municipalities.

After discussions with coordinators in these CAs, the representatives from governing boards and operative groups of the two associations were considered as relevant informants since they are responsible for the running of the CAs, on a strategic and an executive level. All representatives on the boards and operative groups of the two CAs were asked to participate in the study. All accepted; however, one of the interviews was cancelled due to illness. In total, 35 interviews were carried out between August 2007 and March 2008. The interviews lasted for between 32 and 80 minutes and were recorded and transcribed verbatim.

\section{[Table 1 about here]}

The respondents represent a broad variety of organizational backgrounds (table 1), where each category could have been divided further. The category of healthcare 
managers, for instance, includes managers at primary healthcare centres as well as managers in psychiatry. Table 2 shows the distribution of respondents in the organizational structure of the two CAs.

\section{[Table 2 about here]}

\section{Data collection}

Prior to the interviews, an interview guide was developed with questions covering how the coordination is performed in practice; the organization's benefits from participating in the CA; what role the respondent's organization plays in the CA; how the CA is governed; differences and similarities between goals and regulations between the stakeholders; implementation of CA work forms into regular practice; and which target groups should be in focus for the coordination in a longer perspective. The interviews were open-ended, and as the interviews were carried out, new topics for discussion developed. These topics were incorporated into subsequent interviews, and they focused on the organizational relationship between the stakeholders; whether existing work forms are affected by the CAs; the organization of cooperative work forms; long-term or short-term coordination; and communication between participants in the CAs. Since emergent questions were incorporated into subsequent interviews, all interviews covered approximately the same topics.

\section{Method of analysis}

The analysis was performed according to the principles of a qualitative content analysis [15]. Interview transcriptions were read through several times by the first author, which resulted in a preliminary thematization of recurrent issues, covering 
both pre-established domains of interest (such as the organizational benefits of cooperation, differences and similarities in goals, thoughts about implementation) and issues that arose from the discussions with the respondents (communication, organization of cooperative work). Hereby, the analysis can be said to incorporate inductive as well as deductive elements. The suggested thematization was discussed with the co-authors, and revisions were made until agreement was reached on a thematic structure that is well grounded in the empirical material and that shows satisfactory internal homogeneity and external heterogeneity, i.e. that themes are well defined and does not overlap [15]. The theoretical conceptualization was largely chosen on the basis of the results, where the concept of interorganizational trust became central in interpreting the results.

\section{Results}

The respondents generally agree upon the aims of the CAs; they describe the common goals in similar terms that correspond to the stated aims in the preparatory work and activity plans. The guiding principle for most of the representatives of the CAs is to facilitate self-sufficiency for the target group, primarily through employment. Another goal for participation is to reduce the risk of moving people from pillar to post, due to gaps between authorities. Finally, most representatives agree with the goal of reducing costs by coordinating the available resources.

However, while agreeing with the stated aims of the CAs, the interpretation of these aims differs depending on which organization one represents. Stakeholders have 
different views on what the CAs should be used for and how the use of CAs relates to regular practice in their organizations.

\title{
Common goals and stakeholder interests
}

The social insurance agency is the stakeholder whose representatives express the most contented views on the aims and scope of the CA, since the organizational aims of the social insurance agency agree in most respects with the overall aims of CAs and the emphasis on return-to-work. As one representative state, the need for cooperation comes naturally:

\begin{abstract}
The social insurance agency should be the driving authority in cooperation, and since we know that our clients deal with many other authorities it comes quite naturally. This is... I don't feel that this is from an authority perspective; there's an individual perspective on this. I mean, our clients are in contact with the healthcare system anyway in connection with sick listings, for instance. Many also have dealings with the employment services if they don't have an employer. If you have an employer, then it's the healthcare services and us and the employer, since it's the employer who's responsible for the rehabilitation. (SSIA representative)
\end{abstract}

With such a perspective on the need for everyday cooperation, it is easy for the social insurance agency representatives to identify with the aims of the CAs, and thus the congruence between the social insurance agency's organizational goals and the common goals of the CAs is high. The target group of the CAs is also similar to the main target group of the social insurance agency, i.e. the work disabled within the working-age population.

The employment service representatives seem to have more problems with the common goals of the CAs. Firstly, their primary target group is the unemployed that are “job-ready”, i.e. employable. The target group of the CAs most often require further rehabilitation before being considered employable, which causes employment service representatives to express discontent with the priorities of the CAs. 
What's difficult, as I see it, is to disregard our regulations, the primary task of our own organization, when there are projects where you may feel that well, but Christ, this is, it'll take three years before these people can actually be ready for the labour market. (SPES representative)

Secondly, the employment service representatives expressed their scepticism already in the preparatory work for the legislation on which the CAs are based, specifically questioning the use of CAs to facilitate the realization of their organizational goals (Swedish Government 2002). This scepticism is also reflected in the interviews, where a representative from the employment service argues that their organization was forced to be involved, since their participation was a condition for starting a CA.

I don't think our expectations of the activities of the CA are very high. Or, if I speak for myself they weren't. They weren't.

But you still chose to join?

We were forced to join.

What was it that forced the employment service to join?

Well, you feel forced to do it when three parties say: we want to start a CA, and one party says: well, we aren't interested. Then nothing comes of it. (SPES representative)

Involving the employment service into a highly structured cooperation like a CA increases their responsibility in the return-to-work process, which also implies an increase in the other stakeholders' expectations. However, since the employment service representatives feel forced into cooperation, their commitment to the common work is generally low, as is their identification with the common goals and their expectations of outcomes.

Representatives from municipalities and healthcare express more divergent views on the use and purpose of the CAs, due to the broader variety of professional positions of 
the representatives from these stakeholders. Representatives of municipalities include managers in social services as well as municipal politicians, while healthcare representatives consist of politicians as well as managers in primary healthcare centres and psychiatry. Municipal politicians look upon participation in a CA as a way of securing the welfare of the citizens by making the social security system work better. Politicians may therefore be seen as the stakeholder that most distinctly places the individual in focus. Municipal politicians often express a broader perspective on cooperation than representatives from the state-governed authorities (the social insurance agency and the employment service) and social service managers, supposedly since they have an overall responsibility for the citizens and are less limited to organizational regulations.

\begin{abstract}
And since we have the overall responsibility, the resources that we have at our disposal have to be suitable for the individual as far as possible. That the individual has a job, an occupation and security. And we know that it's not only the municipality that provides those resources; the county council does so, and the state, in the form of the social insurance agency and the employment service. [...] And now we can bring the resources together, from the individual perspective. That's the point. But also that we coordinate and gain as much as possible from the resources we put in. (Municipal politician, chairman of a CA)
\end{abstract}

Although healthcare representatives express different views on the purpose and methods of the CAs, a common interest can be determined that differs from the stated aims of the CAs. While the official documents and preparatory work of the CAs identify return-to-work as central to the common work, healthcare representatives tend to place more emphasis on the ways in which their patients' quality of life can be improved.

Well, the employment service has their goals, to get people closer to employment and into employment, and the goal of healthcare wasn't perhaps... That wasn't the most important thing from the beginning, but to, to increase the patient's ability to function, to reduce pain. [...] for the county council or primary healthcare the main objective is still 
to improve functional ability. Our primary goal is not whether people work or not, that's up to others. (Healthcare representative)

Thus, employment is seen as a secondary aim, and the involvement of healthcare services in promoting return-to-work is therefore generally low. One explanation for this may be that the healthcare system is the only one of the four stakeholders that does not have a responsibility for providing benefits; thus, questions of how individuals are provided with income are less interesting for healthcare representatives than ways of improving health and quality of life.

\section{Conflicting priorities}

Because of the relative complexity of the target group of the CAs, measures taken by the associations often require a long-term perspective on individuals' rehabilitation and return-to-work. This is to be contrasted with the often short-term goals of the participating stakeholders, such as keeping budgets in balance. When these logics clash, problems are bound to arise. Especially in times of strain, organizations tend to focus on their primary tasks, leaving other activities out. For instance, social insurance agency representatives report internal organizational demands as obstacles to participation in cooperative work, regardless of the similarities to the CAs regarding goals.

The primary tasks of our respective organizations can also be an obstacle in cooperation sometimes, especially if it's during a period when there have to be cutbacks, staff are dismissed; this means that the activities are hindered considerably. Then sometimes it's hard to focus on cooperation since there are so many internal demands. (SSIA representative)

There is an obvious disagreement in priorities between the employment service and the CAs. Most employment service representatives claim that the activities initiated 
through CAs should focus on short-term measures for people who are close to the labour market. The disagreement becomes even more obvious in discussions about whether CAs should work in a preventive manner, where the employment service representatives are sceptical, arguing that the focus for the CAs should be rehabilitation. Preventive work, according to an employment service representative, cannot be considered until the entire number of disabled people is rehabilitated.

Of course, you can work in a preventive way when you've made sure that those who already have problems won't come back. But of course there are others who would claim that it's really important that we do preventive work, because then no more people will come to [an interdisciplinary team]. But my take on it is still that this [the CAs] developed because it was apparent that many people fell into a grey area. (SPES representative)

Other stakeholders have a different perspective on preventive work, seeing it as a potential for the CAs in managing, or even preventing, work disability. Here the social insurance agency expresses a stance where preventive work is considered as positive and desirable, especially in a long-term perspective.

We look very positively at preventive measures, for example so that we won't get any more but, so to speak, attend to this before they come through the doors of the social insurance agency, so that in the future they're able to provide for themselves, young people for example. Different measures are taken for those who would otherwise be here in ten or fifteen years. (SSIA representative)

Preventive work, in the sense the respondents use it, can be defined both as preventing people from falling ill, i.e. preventing sickness absence altogether, and as placing focus early in the rehabilitation process, i.e. preventing people from becoming longterm disabled. The question of preventive or reactive work serves well as an illustration of conflicting priorities, reflecting the congruence (or lack of it) between the stakeholders and the CA. Here, the self-interest of the stakeholders limits the scope for reaching a common interpretation of the aims of the CAs. Some of the 
municipal politicians also express that their participation in the CAs is based on selfinterest, to secure that their interests are represented and that they receive payback on the money spent on the CAs.

As a municipal representative, what's your role in the CA?

To protect our interests in the CA, that's the number one priority.

What do you mean by protecting your interests?

[...] we put quite a lot of money into the CA and I'm on the board, so I have to see to it that [the municipality] is on the ride and gets something out of it. (Municipal politician)

This view can also be determined among managers in the social services. In one interview, a social service manager argues that their organization participates only to secure that they will receive the funding that they would have had at their own disposal, had it not been for the CAs.

What's supposed to be the new thing is that there's really money in this, that we don't control as managers; instead, so many millions are put into the common pool to be used for these... So it means there's a pressure on us to...

You have to cooperate in some way?

If we want to be able to use the money, we have to be in there. But in a way I think it's sad; did they have to go through all this bureaucracy, because the money won't multiply anyway. (Social services manager)

The representatives generally express self-criticism regarding their self-interest, noting that they tend to want payback, although such an attitude has detrimental effects on the common work. Several respondents claim that the money that is put into the CAs is not primarily supposed to satisfy the stakeholders, but is intended to be used in ways that best serve the target group. 


\section{Crossing borders: a matter of trust?}

Healthcare representatives generally perceive that their role is to make sure that the individual achieves the basic functioning capacity that will make a future return to work possible, implying that their work lies early in the process of returning to the labour market. This can be contrasted with the employment service representatives, who claim that their work comes at the very end of the process, and that they are not interested in participating in earlier stages of return-to-work. Thus, when the participating stakeholders interpret the aims of the CAs, they do so by turning to their organizational goals, and the commitment to CA work forms therefore becomes limited to the projects in which the representatives can identify a specific use for their organization.

\footnotetext{
Primarily we're concerned with the commissions we've been given in our own organizations, and we've said that now we'll sit down and talk in broader terms and... In the CA it works like... I'm most engaged in projects that are connected with my field. (Healthcare representative)
}

The employment service and the healthcare representatives therefore share the view that every stakeholder have their separate responsibilities, and that the purpose of the CAs should be to facilitate the coordination of these responsibilities, and not primarily to initiate concrete cooperative work forms between them. However, the working methods of the CAs have primarily focused on initiating projects in which the stakeholders engage in practical cooperation around specific target groups, which may contribute to limit the commitment to participation. On the other hand, other respondents express that the CAs may contribute to a new way of thinking about responsibilities that would imply better management of the target group, for instance through cooperative work. 
When you're working with an individual and you sit down and plan, the organizational borders don't have to be obstacles that prevent you finding common solutions. My commission doesn't limit my mandate to do a lot. But you can hide behind it. I think there's plenty to do there, and it's actually a matter of a cultural revolution. (Healthcare representative)

Participation in a CA may thus function as a way of finding new interorganizational working methods that lie beyond the regulations of the separate organizations, and possibly even testing the limits of these regulations.

In cooperation we have a better chance of finding solutions for larger groups, also as far as our respective legislations are concerned, solutions that you can't find in regular practice. We have to comply with the law, but we can find other working methods that haven't been tested; it may not be forbidden to try them, but they can be on the border of what's allowed. But normally, those solutions don't exist and there are no ways of working with them because of our limited fields. (SSIA representative)

However, to enable such a cooperative climate, the representatives of boards and other cooperative groups need to identify with the CA as much as with their own organizations, which one respondent identifies as a key question in order to make cooperation work. Such identification is dependent on that all participating organizations will contribute to fulfilling the common goals.

On the boards, the most important thing is to look at this as a common responsibility, so you don't go in and look after your own interests in some way. Because that would very easily mean that you want your invested money back, and the big pedagogical question is always to look at it from above. That you aren't on the board as a representative of one organization alone. Even if I'm a representative for the social insurance agency, as a member of the board I'm a different person who's responsible for the whole thing, so that it works. I can't look at my figures and say that I want payback on them. (SSIA representative)

This identification implies that the representatives’ step back from their organizational self-interest, and that cooperative work need to be upgraded into becoming a primary task in order not to dismiss it when striving to secure financial goals. However, 
cooperation is still often seen as a marginal aspect of daily practice, and all stakeholders are not willing to step back from their self-interest.

When there are complex cases with sickness or something else, then, of course, it's good to have a good working routine in how to get in contact with other authorities. I mean, it's critical also for our work. But if you went out and asked our staff, they would think that it's still on the margin, because it is. (SPES representative)

Especially the employment service representatives seem to prefer that the CA is used as a tool for coordinating the responsibilities of the actors rather than initiating cooperation between them. Thus, there are differences between the stakeholders in how much the CA ought to promote that organizational borders are crossed.

Representatives’ crossing of organizational borders relies on a mutual trust between the participants: that the representatives do not "hide behind their commissions". However, since all stakeholders value their self-interest, trust is dependent on representatives managing to make priorities outside of the main objective of their organization. One municipal politician expresses weariness over the national authorities, in particular the employment service, and its inability to move beyond the regulations.

The CA has to be able to be an arena. [...] I'd like a big meeting where we would be gathered properly from all actors. I think we and [the other municipality] think pretty alike. And the Employment Services, well we have her [SPES representative] at the board, and she's so regimented by their regulations. And now, now it's her, and then there's God in Stockholm above her. There's no one at the county level anymore. And it's hard to make them think differently, I think. (Municipal politician)

Without the leeway to act outside of regular organizational practice, interorganizational cooperation seems less likely to occur. And with suspicion rather 
than trust as a characterizing quality of the cooperation, there are few incentives to prioritize cooperative work.

\section{[Table 3 about here]}

In table 3, the differences between the stakeholders regarding motives for cooperation becomes apparent, where each organization's target group largely defines to what extent the CAs are seen as useful. The congruence between the stakeholders' goals and the common goals of the CAs also differ, where the social insurance agency and the municipalities are more in line with the common goals. Healthcare have an interest in developing a functional cooperation with authorities in sick-listing issues, while the goal of return-to-work is less expressed. The employment service does not seem to have a high interest in cooperation, while their focus on return-to-work is more emphasized. The attitude to cooperation thus seems more decisive than the focus on return-to-work, which is reflected in the commitment to the CAs and the experienced benefit. This would explain why the employment service is less committed to the CAs than is healthcare, despite that both stakeholders have an equal amount of congruence to the goals of the CAs.

\section{Discussion}

The CAs represent an innovative example of stakeholder cooperation in return-towork, which is interesting in the light of the questions posed in the introduction: how stakeholder cooperation should be organized and in what way it should (or could) be regulated. The CAs is a highly structured form of cooperation regulated in legislation. 
Further, all stakeholders contribute with financial and professional resources, which creates a bond that guarantees the durability of the cooperation. This structure generates incentives to make cooperation work. Since the CAs are designed to work solely with coordination of and cooperation between rehabilitation stakeholders, they have a unique intermediary function. However, the involvement of stakeholders in cooperative work is complicated by disagreements regarding priorities.

\section{Trust and distrust in cooperative relations}

The results of this study show that there are many different views on the goals of the CAs, and that the views are closely tied to the organizational goals of the participating stakeholders. There is a superficial consensus about the common goal for cooperation, but the stakeholders interpret this goal according to different principles. Self-interest is a common feature among all the participating stakeholders, which determines the motives for participating in cooperation. These motives are, in turn, more or less congruent to the aim of the CAs (see table 3). It should also be held in mind that the stakeholders' commissions only to a certain degree are congruent with the aim of the CAs. Relating back to figure 1, there is only a slight overlap between the stakeholders and the CAs. In reality, the overlap may be larger or smaller for different stakeholders, but the central commission of each stakeholder is nevertheless different from the common aim. The initial purpose of the CAs was to cover a previously neglected area of responsibility, between the stakeholders, which implies that there is a risk that CAs also will be neglected.

Previous research indicates that goodwill and trust between individuals and rehabilitation stakeholders is a key characteristic of a successful return-to-work process $[3,6]$. It is reasonable to assume that trust is equally important in cooperation 
between rehabilitation stakeholders. According to Dirks and Ferrin, “trust will moderate the relationship between cooperative motives and cooperative behaviour" [16]. They state that the motive for achieving cooperation is a primary determinant for cooperative behaviour, but such motives are insufficient for cooperation to occur. Participants need to expect that also their partners will cooperate. If lacking this expectation, cooperation is not perceived as feasible: under low trust, cooperative motives are unlikely to be translated into cooperative behaviour [16] (cf. [17], chapter 5).

In the CAs, each stakeholder has different motives for cooperation (see table 3). In order to manage these motives and to turn them into cooperative behaviour, trust is an essential feature. But how is trust generated? While acknowledging that goodwill and predictability is generally important for trusting behaviour to occur, Hardy et al argues that trust in interorganizational settings is developed through a communicative process where the partners develop shared meanings as a foundation for nonopportunistic behaviour [18]. That conflicts arise should not necessarily be interpreted negatively. On the contrary, it is argued, conflicts can be understood as a sign that all partners contribute to the creation of shared meaning, contributing to a reciprocal relationship on which trust can be built [18]. Another conceptualization of trust is Zucker's differentiation between process-based trust, based on an earned trust through historical exchange; characteristic-based trust, based on similarity; and institutionalbased trust, based on traditions or regulations [19].

The stakeholders in the CAs have a history of cooperation, although not always in a structured way. After decades of handling borderline cases between authorities, a 
certain process-based trust can be said to have developed. Simultaneously, the CAs represent a legal agreement between the participating stakeholders that may generate a form of institutional trust. However, this structured cooperation puts more demands on the participating stakeholders than did the previous unstructured work routines. This implies that stakeholders need to put in more resources into cooperation to make it work. Thus, for trust to develop within the CAs, shared meanings need to be reached through an extensive reciprocal communication process.

As shown in the results, at least one of the stakeholders in the CAs, the employment service, express dissatisfaction with these demands for cooperative behaviour, and the employment service representatives do not seem to be interested in developing cooperation through institutional agreements. Their interest is limited to coordinating the resources of the participating stakeholders. Also shown in the results, this disinterest and the employment service’s difficulties in seeing beyond their regulations can cause irritation among the other stakeholders. If one stakeholder repeatedly counteracts the common work, there is a risk that distrust is developed.

The literature on distrust relies heavily on Luhmann's analysis of distrust as both the opposite of trust and a functional alternative to it [20] (cf. [21]). Distrust, Luhmann argues, breeds distrust, creating a downward spiral where distrust becomes routine, threatening to counteract cooperation as well as organizational learning [20]. Luhmann argues that most organizations have mechanisms for keeping distrust from becoming destructive, but that there is a threshold effect where distrust no longer can be explained away. 
In the CAs, cooperation has been organized primarily through interorganizational projects with temporary financing through the pooled budget, with the expectation that successful projects will be implemented into regular practice and financed in regular budgets. At the time of writing, attempts of implementation have failed for several projects since the employment service has refused to contribute to the financing. This situation illustrates how one stakeholder may exercise a veto against cooperative projects by resisting paying its share. Thus, the sceptical approach of the employment service that was prevalent in the interviews for this study seem to subsequently have developed into non-cooperative behaviour, which according to Dirks and Ferrin can be interpreted as a result of low trust [16]. In this case, conflicts have thus not resulted in the development of a reciprocal relationship. It is even possible to state that the non-cooperative atmosphere indicates a risk that the stakeholders will enter a downward spiral of distrust, in Luhmann's sense of the word $[20]$.

\section{The importance of institutional structures, or what is Swedish?}

Much of the return-to-work literature originates from Anglo-Saxon countries, e.g.

Canada or the US. When authors from these countries discuss stakeholder cooperation, they do so from the perspective of a liberal welfare state, where much of the responsibility for welfare lies with either the individual or with private actors [7]. The importance of the institutional structure of different welfare systems is reflected in the compensation systems, where there is a more developed public responsibility in the Scandinavian welfare system than in the Anglo-Saxon counterparts. For instance, the employers in the Swedish system only finance the first two weeks of sickness absence, after which the Social Insurance Agency takes over. In addition, the Swedish 
system is a comprehensive system, where a disease does not need to be work related in order to make the individual eligible for sickness benefits. This stands in contrast to cause-based systems, as the North American, where eligibility to compensation is tied to evidence that an injury is caused by work, which implies a process with more litigation and conflict $[22,23]$. One of the consequences of a comprehensive system is that the compensation system needs to administrate a broader set of diagnoses than if the system would have been limited to work injuries.

The Swedish system for return-to-work involves public authorities from the day the individual is sick-listed to the day they return to their work, or if unable to return, to a new employment with assistance from the Public Employment Service. Each of these public authorities has their separate commissions, and thus public authorities are stakeholders in return-to-work, representing different interests. As shown in the results of this study, the self-interest of these stakeholders is prominent and determines whether they manage to cooperate or not. There seems to be a general lack of holism and shared meaning between the authorities.

As Rothstein and Steinmo argue, institutions structure a logic of appropriateness, which means that an actor's preferences are influenced by the context in which they operate [8] (cf. [24]). This socio-cultural perspective on institutional behaviour suggests that individuals cannot be expected to act fully rational in interaction with others. Instead, they follow scripts or templates given to them by the institutions they belong to. In this way, institutions can be considered both shaping and creating preferences. They define actors' identities and shared values, which makes the logic of appropriateness a situational approach to action, since an individual's preferences 
vary in different institutional settings [8]. Applied to the results of this study, the stakeholders in the Swedish system can be said to act from preferences developed in accordance with the commissions of each organization. Taking the employment service as an example, they tend to focus on people who are already considered employable. This could from a holistic perspective be considered irrational, since it implies that they do not consider the whole system when defining their priorities. Still, their actions are rational from an organizational perspective, since they contribute to fulfilling organizational goals. Thus, the employment service adhere more to organizational values than to social or welfare values when determining the logic of appropriateness for their actions (cf. [25]). The logic of appropriateness in this case is scepticism towards cooperative work, which is situated in a perspective on cooperation as a hindrance to fulfilling organizational goals.

\section{Methodological considerations}

This study was carried out within the Swedish welfare system, implying that the perspectives of the respondents are related to specific welfare organizations and how the respondents react to changes in this system. It is however reasonable to assume that the importance of institutional structures for cooperation is relevant also in other national systems.

The approach when performing interviews for the study included several inductive elements. The initial interview guide was used throughout the interview process, although new topics were added on the basis of issues that previous respondents chose to mention. The interview process was thus intentionally open to changes in order to follow up themes that the respondents found relevant. This iterative process of data 
gathering and analysis adds to the validity of the study by allowing it to explore the respondents' views more in depth, and to better mirror the views and problems that the respondents express as representatives of CAs and other organizations [15].

Finally, it should be noted that the differences between the two CAs in the study were small, which suggests that differing views on cooperation should be attributed to the stakeholders' organizational values rather than to the local context in which a CA operates. However, since only two CAs were included in the study, it should be taken into consideration that CAs may operate differently in other parts of the country with different demographical conditions.

\section{Conclusions}

The aim of this study was to explore different public stakeholders' views on and experiences of participating in CAs, a highly structured form of cooperation in returnto-work. The existence of CAs show that it is possible to create long-term cooperative structures through legislation, but the experiences from the CAs suggest that the sustainability of cooperation is dependent on the level of mutual trust between the participating organizations. Stakeholders' actions are to a high degree determined by their institutional preferences, and when such preferences counteract cooperative work, there is a risk that cooperation is spoiled. The cooperative motives are, then, not always translated into cooperative behaviour.

In the CAs, it is obvious that the motives for cooperation differ between the stakeholders, and that although these differences supposedly could be overcome, they 
are in fact not. One of the stakeholders, the Public Employment Service, limit its interest to coordinating resources, while the other three wishes to engage in elaborated cooperative work forms, implying the crossing of organizational borders. This discrepancy can largely be attributed to the difficulties for representatives from national authorities to change their priorities in order to make cooperation work.

This study shows that stakeholders' interests have a high impact on the prerequisites for cooperation in return-to-work. By referring to organizational goals, stakeholders engage in non-cooperative behaviour, which threatens to spoil cooperative initiatives and to develop distrust in cooperative work forms. As shown, trust is a key condition in stakeholder cooperation, while self-interest and low trust impedes the development of functional intermediary actors in return-to-work. By pointing at the conditions for interorganizational trust to develop, the results of this study thus expose the complexity of cooperation, and what threatens it. As such, the conclusions from this study may be used by return-to-work stakeholders in different jurisdictions to improve the possibilities for the development of cooperative structures.

\section{Acknowledgements}

We are grateful to the coordinators in the two CAs for their help in opening doors to the respondents in this study. 


\section{References}

[1] Brunarski D, Shaw L, Doupe L. Moving toward virtual interdisciplinary teams and a multi-stakeholder approach in community-based return-to-work care. Work. 2008;30(3):329-336.

[2] Franche R-L, Baril R, Shaw W, Nicholas M, Loisel P. Workplace-Based Return-to-Work Interventions: Optimizing the Role of Stakeholders in Implementation and Research. Journal of Occupational Rehabilitation. 2005;15(4):525-542.

[3] Friesen MN, Yassi A, Cooper J. Return-to-work: The importance of human interactions and organizational structures. Work. 2000;17(1):11-22.

[4] Loisel P, Durand M-J, Berthelette D, Vézina N, Baril R, Gagnon D, et al. Disability Prevention: New Paradigm for the Management of Occupational Back Pain. Disease Management and Health Outcomes. 2001;9(7):351-360.

[5] Loisel P, José-Durand M, Baril R, Gervais J, Falardeau M. Interorganizational Collaboration in Occupational Rehabilitation: Perceptions of an Interdisciplinary Rehabilitation Team. Journal of Occupational Rehabilitation. 2005;15(4):581-590.

[6] MacEachen E, Clarke J, Franche R-L. Systematic review of the qualitative literature on return to work after injury. Scandinavian Journal of Work, Environment and Health. 2006;32(4):257-269.

[7] Esping-Andersen G. The Three Worlds of Welfare Capitalism. Cambridge: Polity Press 1990.

[8] Rothstein B, Steinmo S. Restructuring Politics: Institutional Analysis and the Challenges of Modern Welfare States. In: Rothstein B, Steinmo S, eds. Restructuring the Welfare State: Political Institutions and Policy Change. New York: Palgrave MacMillan 2002.

[9] de Bakker FGA, den Hond F. Introducing the Politics of Stakeholder Influence: A Review Essay. Business \& Society. 2008;47(8):8-20.

[10] Rowley TJ, Moldoveanu M. When Will Stakeholder Groups Act? An Interestand Identity-Based Model of Stakeholder Group Mobilization. The Academy of Management Review. 2003;28(2):204-219.

[11] Korpi W, Palme J. The paradox of redistribution and strategies of equality: Welfare state institutions, inequality, and poverty in the Western countries. American Sociological Review. 1998;63(5):661-687.

[12] Transforming Disability into Ability: Policies to Promote Work and Income Security for Disabled People. Paris: Paris: Organisation for Economic Co-Operation and Development (OECD); 2003.

[13] Prins R. Integrated Services in Rehabilitation - on Coordination of Organization and Financing: Synthesis Report: European Commission; 2006. 
[14] Jakobsson B, Bergroth A, Schüldt K, Ekholm J. Do systematic multiprofessional rehabilitation group meetings improve efficiency in vocational rehabilitation? Work. 2005;24:279-290.

[15] Patton MQ. Qualitative research and evaluation methods. 3 ed. London: Sage 2002.

[16] Dirks KT, Ferrin DL. The Role of Trust in Organizational Settings. Organization Science. 2001;12(4):450-467.

[17] Rothstein B. Just institutions matter: The moral and political logic of the universal welfare state. Cambridge: Cambridge University Press 1998.

[18] Hardy C, Phillips N, Lawrence T. Distinguishing Trust and Power in Interorganizational Relations: Forms and Facades of Trust. In: Lane C, Bachmann R, eds. Trust Within and Between Organizations. New York: Oxford University Press 2000.

[19] Zucker LG. Production of Trust: Institutional Sources of Economic Structure, 1840-1920. Research in Organizational Behaviour. 1986;8:53-111.

[20] Luhmann N. Trust and Power: Two Works. Chichester: Wiley 1979.

[21] Lane C. Introduction: Theories and Issues in the Study of Trust. In: Lane C, Bachmann R, eds. Trust Within and Between Organizations. New York: Oxford University Press 2000.

[22] Cox R, Lippel K. Falling through the legal cracks: The pitfalls of using workers' compensation data as indicators of work-related injuries and illnesses. Policy and Practice in Health and Safety. 2008;6(2):63-84.

[23] Lippel K. Therapeutic and anti-therapeutic consequences of workers' compensation. International Journal of Law and Psychiatry. 1999;22(5-6):521-546.

[24] Powell WW, DiMaggio PJ. The New Institutionalism in Organizational Analysis. Chicago: University of Chicago Press 1991.

[25] Simon HA. Administrative Behavior: A Study of Decision-making Processes in Administrative Organizations. 4 ed. New York: The Free Press 1947/1997. 


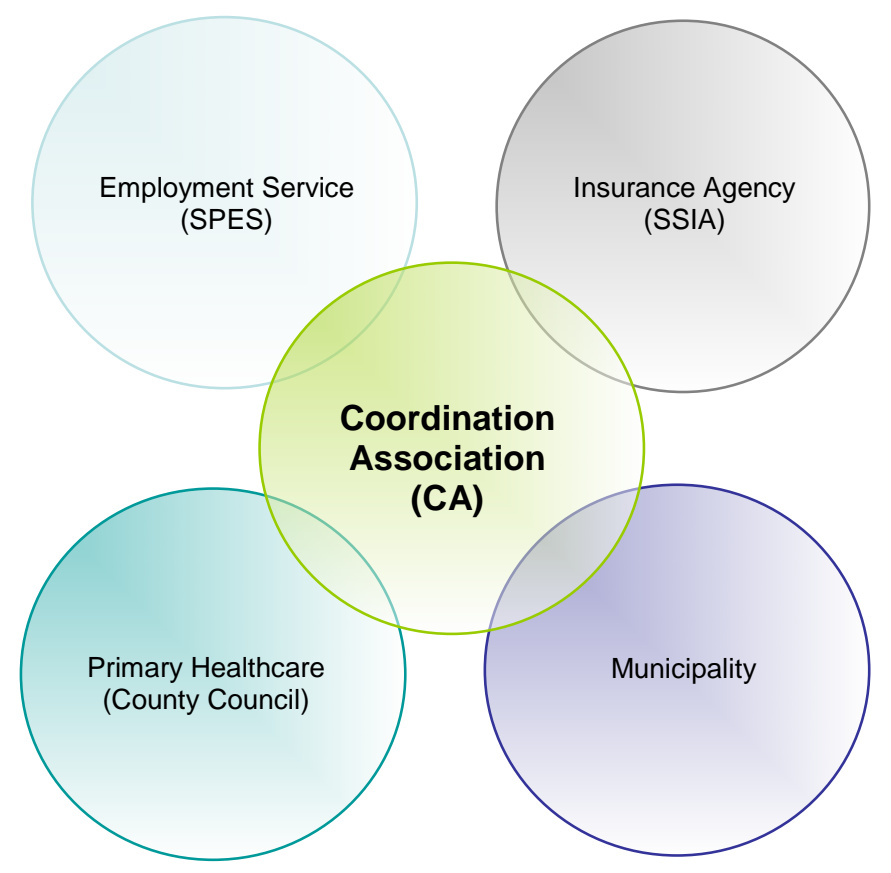

Figure 1: CAs relationship to the participating stakeholders. 
Table 1: Overview of the respondents showing the organizations they belong to

\begin{tabular}{|lr}
\hline Municipal politicians & 6 \\
Municipal managers & 5 \\
County council politicians & 3 \\
Healthcare managers & 10 \\
SSIA officials & 5 \\
SPES officials & 5 \\
Administrative staff & 1 \\
Total & 35 \\
\hline
\end{tabular}

Table 2: Overview of the categories to which the respondents belong in the CAs

\begin{tabular}{|lr}
\hline CA 1 Board & 7 \\
CA 1 Operative group & 9 \\
CA 1 Administrative staff & 1 \\
CA 2 Board & 9 \\
CA 2 Operative group & 9 \\
Total & 35 \\
\hline
\end{tabular}


Table 3: Summary and interpretation of the stakeholders' interests in and commitment to the CAs

\begin{tabular}{|c|c|c|c|c|c|}
\hline & $\begin{array}{l}\text { Insurance } \\
\text { Agency } \\
\text { (SSIA) }\end{array}$ & $\begin{array}{l}\text { Employment } \\
\text { Service } \\
\text { (SPES) }\end{array}$ & $\begin{array}{l}\text { Primary } \\
\text { Healthcare }\end{array}$ & Municipalities & $\begin{array}{l}\text { Coordination } \\
\text { Association }\end{array}$ \\
\hline $\begin{array}{l}\text { Primary target } \\
\text { group }\end{array}$ & $\begin{array}{l}\text { Work disabled, } \\
\text { working-age }\end{array}$ & $\begin{array}{l}\text { Employable, } \\
\text { working-age }\end{array}$ & $\begin{array}{l}\text { Sick, ill and/or } \\
\text { disabled, all } \\
\text { ages }\end{array}$ & $\begin{array}{l}\text { Socially excluded, } \\
\text { unemployed, } \\
\text { disabled, all ages }\end{array}$ & $\begin{array}{l}\text { Work disabled, } \\
\text { socially } \\
\text { excluded, } \\
\text { unemployed, } \\
\text { working-age }\end{array}$ \\
\hline $\begin{array}{l}\text { Motives for } \\
\text { cooperation }\end{array}$ & $\begin{array}{l}\text { RTW for work } \\
\text { disabled, } \\
\text { efficiency }\end{array}$ & $\begin{array}{l}\text { RTW for } \\
\text { unemployed, } \\
\text { efficiency }\end{array}$ & $\begin{array}{l}\text { Individual } \\
\text { health and } \\
\text { quality of life, } \\
\text { cooperative } \\
\text { work }\end{array}$ & $\begin{array}{l}\text { Self-sufficiency, } \\
\text { social security, } \\
\text { efficiency }\end{array}$ & $\begin{array}{l}\text { RTW for } \\
\text { disadvantaged } \\
\text { groups }\end{array}$ \\
\hline $\begin{array}{l}\text { Priority in RTW } \\
\text { process }\end{array}$ & Early-mid & Late & Early & Early-late & Early-late \\
\hline $\begin{array}{l}\text { Congruence } \\
\text { with CA goals }\end{array}$ & High & Low/Medium & Low/medium & High & $\mathrm{N} / \mathrm{A}$ \\
\hline $\begin{array}{l}\text { Experienced } \\
\text { benefit/value of } \\
\text { participation }\end{array}$ & $\begin{array}{l}\text { High: RTW is a } \\
\text { central issue }\end{array}$ & $\begin{array}{l}\text { Low: wants more } \\
\text { short-term efforts }\end{array}$ & $\begin{array}{l}\text { Medium: low } \\
\text { interest in RTW, } \\
\text { high interest in } \\
\text { cooperative } \\
\text { work }\end{array}$ & $\begin{array}{l}\text { Medium/high: } \\
\text { wants more long- } \\
\text { term efforts }\end{array}$ & $\mathrm{N} / \mathrm{A}$ \\
\hline $\begin{array}{l}\text { Commitment to } \\
\text { the CAs }\end{array}$ & High & Low & Medium & Medium/high & $\mathrm{N} / \mathrm{A}$ \\
\hline
\end{tabular}

